\title{
Brain Awareness Week, CoVID-19 infection and Neurological Sciences
}

\section{Antonio Federico ${ }^{1}$}

Published online: 16 March 2020

(C) Fondazione Società Italiana di Neurologia 2020

Brain Awareness Week is the global campaign to foster public enthusiasm and support for brain science. Every March, "partners host imaginative activities in their communities that share the wonders of the brain and the impact brain science has on our everyday lives".

Brain Awareness Week's 25th anniversary campaign has taken place from March 16-22, 2020 but unfortunately the majorities of the planned activities has been cancelled because Coronavirus 19 pandemic infection.

Universities are closed in many countries, with web teaching substitutions; people are requested to stay at home to slow the epidemic infection spreading; the hospitals are under stress because of the high number of patients in intensive care units requiring respiratory supports.

In many hospitals, neurologic departments have been limited in their spaces, to host COVID-19 patients and all doctor community is involved in the care of this infections, that is much more severe in fragile patients, as those of old age, affected by neurodegenerative diseases.

We don't have to forget the many doctors were infected and died : one of them was dr. Ivo Cillesi (61 years), an expert of Alzheimer's diseases, and one of the main supporter of the use of the "doll therapy" to improve anxiety and give relaxation to Alzheimer's patients .

For this Brain Awareness Week's $25^{\text {th }}$ anniversary, the Italian Society of Neurology (SIN) gave a title RIsinG the Brain inviting to divulgate all the news for therapy, care and diagnosis of the neurologic disorders.

Neurologic Sciences, as done in the past years, selected the most cited articles published in the past year and granted free access to them one month (Table 1).

Antonio Federico

antonio.federico@unisi.it

1 Department Medicine, Surgery an Neurosciences, Medical School, University of Siena, Viale Bracci 2, 53100 Siena, Italy
Table 1 Values obtained through the SIMPER analysis based in the diet of the Crenicichla species from streams, Upper Jacuí and Ibicuí subbasins, Southern Brazil

- Kocaturk, O., Besli, F., Gungoren, F. et al. [1]

The relationship among neutrophil to lymphocyte ratio, stroke territory, and 3-month mortality in patients with acute ischemic stroke

- Vita, G., Vita, G.L., Musumeci, O. et al. [2] Genetic neuromuscular disorders: living the era of a therapeutic revolution.

Part 2: diseases of motor neuron and skeletal muscle

- Park, S.B., Kwon, K., Lee, J. et al. [3] Lack of association between dopamine transporter loss and non-motor symptoms in patients with Parkinson's disease: a detailed PET analysis of 12 striatal subregions

- Hadjigeorgiou, G.M., Kountra, P., Koutsis, G. et al. [4] Replication study of GWAS risk loci in Greek multiple sclerosis patients

- Kaur, R., Mehan, S. \& Singh, S. [5] Understanding multifactorial architecture of Parkinson's disease: pathophysiology to management

- Defazio, G., Albanese, A., Pellicciari, R. et al [6] Expert recommendations for diagnosing cervical, oromandibular, and limb dystonia

- Sansone, V.A., Albamonte, E., Salmin, F. et al. [7] Intrathecal nusinersen treatment for SMA in a dedicated neuromuscular clinic: an example of multidisciplinary and integrated care

- Buture, A., Ahmed, F., Dikomitis, L. et al. . [8] Systematic literature review on the delays in the diagnosis and misdiagnosis of cluster headache

- Tarai, B., Das, P. [9] FilmArray (R) meningitis/encephalitis (ME) panel, a rapid molecular platform for diagnosis of CNS infections in a tertiary care hospital in North India: one-and-half-year review

- Trojano, M., Bergamaschi, R., Amato, M.P. et al. [10] The Italian multiple sclerosis register

- Luo, L., Song, Z., Li, X. et al. [11] Efficacy and safety of edaravone in treatment of amyotrophic lateral sclerosisa systematic review and meta-analysis

- Smirni, D., Smirni, P., Di Martino, G. et al. [12] Early detection of memory impairments in older adults: standardization of a short version of the verbal and nonverbal Recognition Memory Test

- Mohammad, Y., Almutlaq, A., Al-Ruwaita, A. et al. [13] Stroke during sleep and obstructive sleep apnea: there is a link

- Castelnovo, V., Caminiti, S.P., Riva, N. et al. [14] Heterogeneous brain FDG-PET metabolic patterns in patients with C9orf72 mutation

- Bianchi, M.L.E., Riboldazzi, G., Mauri, M. et al. . [15] Efficacy of safinamide on non-motor symptoms in a cohort of patients affected by idiopathic Parkinson's disease

Fang, X. [16] Microbial treatment: the potential application for Parkinson's disease 


\section{Compliance with ethical standards}

Conflict of interest None.

Ethical approval None

\section{References}

1. Kocaturk, O., Besli, F., Gungoren, F. et al. The relationship among neutrophil to lymphocyte ratio, stroke territory, and 3-month mortality in patients with acute ischemic stroke. Neurol Sci 40, 139-146 (2019). https://doi.org/https://doi.org/10.1007/s10072-018-3604-y

2. Vita, G., Vita, G.L., Musumeci, O. et al. Genetic neuromuscular disorders: living the era of a therapeutic revolution. Part 2: diseases of motor neuron and skeletal muscle. Neurol Sci 40, 671-681 (2019). https://doi.org/https://doi.org/10.1007/s10072-019-03764-z

3. Park, S.B., Kwon, K., Lee, J. et al. Lack of association between dopamine transporter loss and non-motor symptoms in patients with Parkinson's disease: a detailed PET analysis of 12 striatal subregions. Neurol Sci 40, 311-317 (2019). https://doi.org/https:// doi.org/10.1007/s10072-018-3632-7

4. Hadjigeorgiou, G.M., Kountra, P., Koutsis, G. et al. Replication study of GWAS risk loci in Greek multiple sclerosis patients. Neurol Sci 40, 253-260 (2019). https://doi.org/https://doi.org/10. 1007/s10072-018-3617-6

5. Kaur, R., Mehan, S. \& Singh, S. Understanding multifactorial architecture of Parkinson's disease: pathophysiology to management. Neurol Sci 40, 13-23 (2019). https://doi.org/https://doi.org/10. 1007/s10072-018-3585-x

6. Defazio, G., Albanese, A., Pellicciari, R. et al. Expert recommendations for diagnosing cervical, oromandibular, and limb dystonia. Neurol Sci 40, 89-95 (2019). https://doi.org/https://doi.org/10. 1007/s10072-018-3586-9

7. Sansone, V.A., Albamonte, E., Salmin, F. et al. Intrathecal nusinersen treatment for SMA in a dedicated neuromuscular clinic: an example of multidisciplinary and integrated care. Neurol Sci 40, 327-332 (2019). https://doi.org/https://doi.org/10.1007/s10072018-3622-9
8. Buture, A., Ahmed, F., Dikomitis, L. et al. Systematic literature review on the delays in the diagnosis and misdiagnosis of cluster headache. Neurol Sci 40, 25-39 (2019). https://doi.org/https://doi. org/10.1007/s10072-018-3598-5

9. Tarai, B., Das, P. FilmArray® meningitis/encephalitis (ME) panel, a rapid molecular platform for diagnosis of CNS infections in a tertiary care hospital in North India: one-and-half-year review. Neurol Sci 40, 81-88 (2019). https://doi.org/https://doi.org/10.1007/ s10072-018-3584-y

10. Trojano, M., Bergamaschi, R., Amato, M.P. et al. The Italian multiple sclerosis register. Neurol Sci 40, 155-165 (2019). https:// doi.org/https://doi.org/10.1007/s10072-018-3610-0

11. Luo, L., Song, Z., Li, X. et al. Efficacy and safety of edaravone in treatment of amyotrophic lateral sclerosis - a systematic review and meta-analysis. Neurol Sci 40, 235-241 (2019). https://doi.org/ https://doi.org/10.1007/s10072-018-3653-2

12. Smirni, D., Smirni, P., Di Martino, G. et al. Early detection of memory impairments in older adults: standardization of a short version of the verbal and nonverbal Recognition Memory Test. Neurol Sci 40, 97-103 (2019). https://doi.org/https://doi.org/10. 1007/s10072-018-3587-8

13. Mohammad, Y., Almutlaq, A., Al-Ruwaita, A. et al. Stroke during sleep and obstructive sleep apnea: there is a link. Neurol Sci $\mathbf{4 0}$, 1001-1005 (2019). https://doi.org/https://doi.org/10.1007/s10072019-03753-2

14. Castelnovo, V., Caminiti, S.P., Riva, N. et al. Heterogeneous brain FDG-PET metabolic patterns in patients with C9orf72 mutation. Neurol Sci 40, 515-521 (2019). https://doi.org/https://doi.org/10. 1007/s10072-018-3685-7

15. Bianchi, M.L.E., Riboldazzi, G., Mauri, M. et al. Efficacy of safinamide on non-motor symptoms in a cohort of patients affected by idiopathic Parkinson's disease. Neurol Sci 40, 275-279 (2019). https://doi.org/https://doi.org/10.1007/s10072-018-3628-3

16. Fang, X. Microbial treatment: the potential application for Parkinson's disease. Neurol Sci 40, 51-58 (2019). https://doi.org/ https://doi.org/10.1007/s10072-018-3641-6

Publisher's note Springer Nature remains neutral with regard to jurisdictional claims in published maps and institutional affiliations. 